\title{
Variations of Twentieth-Century Temperature and Precipitation Extreme Indicators in the Northeast United States
}

\author{
Michael L. Griffiths And Raymond S. Bradley \\ Climate System Research Center, Department of Geosciences, University of Massachusetts-Amherst, Amherst, Massachusetts
}

(Manuscript received 17 July 2006, in final form 5 January 2007)

\begin{abstract}
An examination of five temperature and five precipitation extreme indicators reveals an increase in both temperature and precipitation extremes over the 1926-2000 period in the northeast United States, with most of this increase occurring over the past four decades. Empirical orthogonal function (EOF) analysis of winter frost days (FD) and warm nights (TN90) and also winter consecutive dry days (CDD) and very wet days (R95T) over the 1950-2000 period reveals that some of the variability associated with changes in these extremes may be explained by variations in the Arctic Oscillation (AO), El Niño-Southern Oscillation (ENSO), and Pacific-North American (PNA) pattern. The most prominent feature of these results was the high correlation between the leading EOF of frost days and warm nights and the AO. Winter composites of temperature and precipitation extreme indicators were examined for different phases of the AO and ENSO during the 1926-2000 period. Overall, the AO is a better predictor of winter warm nights, while the ENSO is a better predictor of consecutive dry days in the northeast United States.
\end{abstract}

\section{Introduction}

One of the major concerns related to anthropogenic climate change is an increase in extreme events that could have a profound impact on both human society and the natural environment. Population and infrastructure continues to increase in areas that are vulnerable to extremes such as flooding, storm damage, and extreme heat or cold (Easterling et al. 2000b). Past studies have examined the changes in extreme indicators on a global scale (see, e.g., Frich et al. 2002; Alexander et al. 2006) and also over large regions such as Europe (see, e.g., Klein Tank and Können 2003; Moberg and Jones 2005) and the conterminous United States (see, e.g., Karl et al. 1996; Kunkel et al. 1999; DeGaetano and Allen 2002). In addition, several studies of extremes of temperature and precipitation in the northeast quadrant of the United States have been undertaken. Cooter and Leduc (1995) examined the frost date trends from the 1950s to 1990s and concluded that the start of the frost-free season occurred 11 days ear-

Corresponding author address: Michael L. Griffiths, Environmental and Climate Change Research Group, School of Environmental and Life Sciences, The University of Newcastle, Callaghan 2308, New South Wales, Australia.

E-mail: Michael.Griffiths@studentmail.newcastle.edu.au lier in the mid-1990s than in the 1950s. Clean AirCool Planet and Wake (2005) noted that the growing season length (GSL) in the northeast United States has had an overall increase of eight days during the twentieth century, based on an average of data from seven stations. However, some stations have had a dramatic change in the GSL. An example is Atlantic City, New Jersey, which has had an overall increase in the growing season of five weeks since records began in 1874 . DeGaetano (1996) analyzed changes in the annual number of daily minimum temperature threshold exceedances between 1951 and 1993 from a network of 22 primarily rural sites in the northeastern United States. Results of this analysis indicate an overall statistically significant trend toward fewer cold minimum temperature threshold exceedances across the region (i.e., all stations show a decreasing trend in days with minimum temperatures $\leq-15.0^{\circ} \mathrm{C}$ over this time period). Similarly, substantial increases in the exceedance of warm minimum temperature thresholds were evident at more stations than would be expected by chance.

Trends in one-day and multiday heavy precipitation events in the United States and other countries show a tendency toward more days with heavy precipitation totals over the twentieth century. The annual number of days exceeding 50.8 and $101.6 \mathrm{~mm}$ of precipitation has increased in the United States since 1910 (Easter-

DOI: $10.1175 / 2007 J C L I 1594.1$ 
ling et al. 2000a,b). Karl et al. (1996) found that the proportion of the United States with a much greater than normal number of wet days (days with precipitation greater than or equal to $1 \mathrm{~mm}$ ) has increased much more than would be expected in a stationary climate. They noted that this trend is especially apparent between 1910 and 1940 and after about 1970. The northeast United States has seen an annual average increase in precipitation of $\sim 84 \mathrm{~mm}$ over the last century. Clean Air-Cool Planet and Wake (2005) examined the number of intense precipitation events $(>50.8 \mathrm{~mm}$ of rain in a 48-h period) each year for the period 1888 to 2000. The results of his analysis indicate an increase in extreme precipitation events during the 1980s and 1990s, compared with the early 1900s, for every station investigated in the Northeast.

An important aspect of the analysis of climatic extremes is to consider the difference between the detection of a change and the attribution of change to some identifiable climate forcing factor (Easterling et al. 2000b). Although the frequency and intensity of climate extremes is expected to increase on a global scale with increasing greenhouse gas emissions (Houghton et al. 2001), the response of these extremes to changes in modes of atmospheric circulation is less understood.

This study examines trends in daily extremes of both temperature and precipitation in the northeast United States, for the 1926 to 2000 period, based on 10 extreme indicators recommended by the joint working group on climate change detection of the World Meteorological Organization-Commission for Climatology (WMOCCL) and the Research Program on Climate Variability and Predictability (CLIVAR; Peterson et al. 2001); these indicators were also used by Frich et al. (2002). Trends for these extreme indicators were analyzed for the region to identify the changes in extremes geographically and over time. This paper also examines the influence of three teleconnection patterns [i.e. the Arctic Oscillation (AO), the Pacific-North American pattern (PNA), and the El Niño-Southern Oscillation (ENSO)] on four winter extreme indicators. The next section examines trends in temperature and precipitation extremes over the 1926 to 2000 period, while section 3 looks at the influence of atmospheric circulation modes on four winter extremes. A discussion and overall summary are presented in section 4 .

\section{Climate extremes}

a. Data

Daily maximum and minimum temperatures and daily total precipitation amounts, which were used to

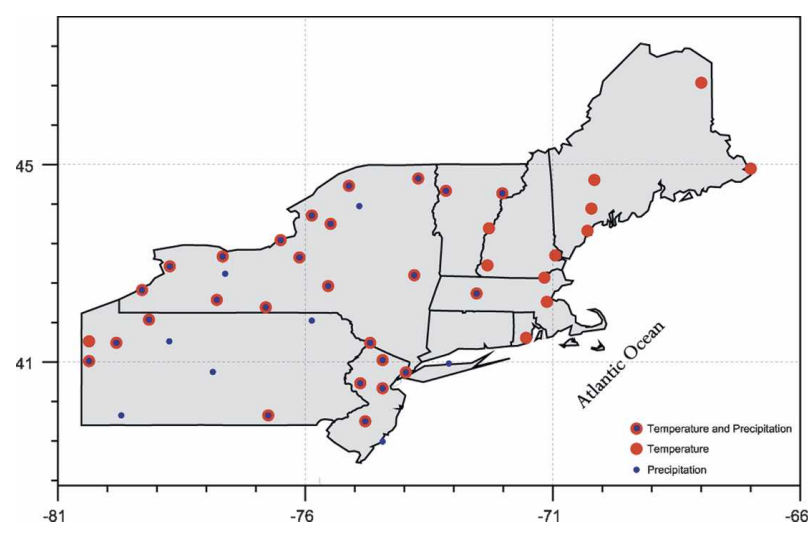

FIG. 1. Locations of meteorological stations used in the analysis of climatic extremes. The symbols classify the stations with temperature records (red); precipitation records (blue); or both temperature and precipitation records (blue and red).

calculate climatic extremes, were obtained from the U.S. Historical Climatology Network (USHCN) daily dataset (Easterling et al. 1999). Prior to publication of the USHCN daily dataset, extensive quality control (QC) checks were conducted by the National Oceanographic and Atmospheric Administration's (NOAA's) National Climate Data Center (NCDC). These QC checks involved examining the data for completeness, reasonableness, and accuracy.

When using daily data to analyze a set of extreme climatic indicators, it is essential that the daily data be almost (if not entirely) complete within the specified interval of time. In addition, when analyzing trends over longer periods, it is essential that years with missing data are few and not clustered together over an interval, as this interval may have a climate that is anomalous compared to the rest of the record. It is for these reasons that rather strict criteria were applied in selecting stations to be used in the analysis. These criteria, which are similar to those used by Moberg and Jones (2005), include the following:

(i) If there are less than or equal to 5 missing days within a month, then that month is considered to have sufficiently complete data.

(ii) A year is considered as complete if all months are complete according to (i).

(iii) A station is considered to have complete data if all four blocks, 1926-44, 1945-63, 1964-82, and 19832000 , each have less than or equal to 5 missing years according to (ii).

Based on these criteria, a total of 38 stations were used in the analysis of temperature extremes and 34 in the analysis of precipitation extremes (Fig. 1). 
TABLE 1. Extreme climate indicators.

\begin{tabular}{|c|c|c|}
\hline Indicator & Definition & Unit \\
\hline \multicolumn{3}{|l|}{ Temperature } \\
\hline Frost days (FD) & $\begin{array}{l}\text { Total number of frost days (days with absolute minimum temperature } \\
<0^{\circ} \mathrm{C} \text { ) }\end{array}$ & days \\
\hline Extreme temperature range (ETR) & $\begin{array}{l}\text { Intra-annual ETR: difference between the highest temperature of any } \\
\text { given calendar year }\left(T_{h}\right) \text { and the lowest temperature reading of the } \\
\text { same calendar year }\left(T_{1}\right)\end{array}$ & ${ }^{\circ} \mathrm{C}$ \\
\hline Growing season length (GSL) & $\begin{array}{l}\text { Period between when } T_{\text {day }}>5^{\circ} \mathrm{C} \text { for }>5 \text { days and } T_{\text {day }}<5^{\circ} \mathrm{C} \text { for } \\
>5 \text { days }\end{array}$ & days \\
\hline Heat wave duration index (HWDI) & $\begin{array}{l}\text { Maximum period }>5 \text { consecutive days with } \mathrm{T}_{\max }>5^{\circ} \mathrm{C} \text { above the } \\
1961-90 \text { daily } \mathrm{T}_{\max } \text { normal }\end{array}$ & days \\
\hline Warm nights (TN90) & Percent of time $T_{\min }>90$ th percentile of daily minimum temperature & $\%$ \\
\hline \multicolumn{3}{|l|}{ Precipitation } \\
\hline Heavy precipitation days (R10) & Number of days with precipitation $\geq 10 \mathrm{~mm} \mathrm{day}^{-1}$ & days \\
\hline Consecutive dry days (CDD) & Maximum number of CDD $\left(R_{\text {day }}<1 \mathrm{~mm}\right)$ & days \\
\hline Maximum 5-day precipitation total (R5d) & Maximum 5-day precipitation total & $\mathrm{mm}$ \\
\hline Simple daily intensity index (SDII) & Annual total precipitation/number of $R_{\text {day }} \geq 1 \mathrm{~mm}$ day $^{-1}$ & $m m$ day $^{-1}$ \\
\hline Very wet days (R95T) & $\begin{array}{l}\text { Fraction of annual total precipitation due to events exceeding the } \\
1961-9095 \text { th percentile }\end{array}$ & $\%$ \\
\hline
\end{tabular}

$T_{\text {day }}=$ mean temperature for a given day.

$T_{\max }=$ maximum temperature.

$T_{\text {min }}=$ minimum temperature.

$R_{\text {day }}=$ daily precipitation .

\section{b. Methods}

\section{1) Climate extreme indicators}

Ten climate extreme indices (from over 50 in the WMO-CCL/CLIVAR list) were used to assess the changes in extremes for the northeast United States on annual time scales. In addition, 4 of the 10 indices were calculated for the winter months [December-March (DJFM)] to examine the possible influence of teleconnections on these extremes.

These 10 indices (also used by Alexander et al. 2006) include 5 temperature and 5 precipitation indices (Table 1). Of the five extreme precipitation indices, four of them relate to "wetness" (R10, R5d, SDII, and R95T) while one of them relates to "dryness" [consecutive dry days (CDD)]. R10 is an indicator of the frequency of significant precipitation days for a given year, while R95T and R5d measure the magnitude of the more intense precipitation events. In contrast, the SDII is a measure of the average amount of precipitation that falls on a wet day in a given year. Last, the CDD index is a measure of the length of the driest part of the year; this indicator may serve as a useful measure of drought conditions.

Four of the five extreme temperature indicators [frost days (FD), extreme temperature rang (ETR), GSL, and heat wave duration index (HWDI)] are absolute measures while one of them is a percentile-based measure (TN90). The FD indicator measures the number of frost days a particular location receives for a given year. The intra-annual ETR is the difference between the highest maximum temperature for summer and the lowest minimum temperature for winter. The HWDI is a useful indicator for measuring prolonged periods of summer heat stress calculated from daily maximum temperatures. TN90 measures the occurrence of warm nights, expressed as the percentage of days where minimum temperatures exceed the 90th percentile of the distribution for a given year or season. Last, the GSL indicator, which is defined as the length of the period between the first spell of five consecutive days with mean temperature above $5^{\circ} \mathrm{C}$ above and the last such spell of the year, is a useful index of spring and autumn conditions.

\section{2) Trend analysis}

Although a variety of studies have analyzed trends in climatic extremes both globally (e.g., Frich et al. 2002; Kiktev et al. 2003; Alexander et al. 2006) and regionally (e.g., DeGaetano 1996; Plummer et al. 1999; Klein Tank and Können 2003), few have examined trends of a series beginning prior to the second half of the twentieth century.

This analysis involved calculating trends in the extreme indices for each station for three separate intervals: 1926-2000, 1926-60, and 1961-2000. Despite the fact that the ordinary least squares (OLS) method of trend fitting has its limitations (e.g., autocorrelation and nonnormal distribution), it is the most widely used and accepted method in the literature. The 1926-2000 
TABLE 2. Percentage of stations with trends in temperature indices that are significant at the $5 \%$ level.

\begin{tabular}{|c|c|c|c|c|c|c|}
\hline \multirow[b]{2}{*}{ Extreme indicator } & \multicolumn{2}{|c|}{ 1926-2000 } & \multicolumn{2}{|c|}{$1926-60$} & \multicolumn{2}{|c|}{ 1961-2000 } \\
\hline & Positive & Negative & Positive & Negative & Positive & Negative \\
\hline FD & 16 & 21 & 16 & 5 & 3 & 16 \\
\hline ETR & 0 & 10 & 2.5 & 0 & 0 & 40 \\
\hline GSL & 24 & 5 & 5 & 0 & 17 & 0 \\
\hline HWDI & 13 & 21 & 37 & 0 & 13 & 13 \\
\hline TN90 & 23 & 18 & 23 & 13 & 31 & 3 \\
\hline
\end{tabular}

interval was chosen since it is the longest common period possible with the available data for the region. The 1926-60 and 1961-2000 periods were chosen as they approximate each half of the longer interval. Furthermore, since most of the recent warming has occurred during the latter half of the twentieth century, examining changes between these two intervals may help shed light on whether changes may be related to anthropogenic effects on global temperatures.

Statistical significance was assessed using a so-called moving-block bootstrap method. This technique, which is identical to that of Kiktev et al. (2003) in their study of globally gridded temperature extremes, involves the random resampling of time series for each station 1000 times, to produce 1000 time series that could have plausibly occurred in the real world. Instead of resampling each year separately, consecutive years [or "blocks" of years with block length $(L)]$ of the original time series are resampled so as to preserve the autocorrelation. The climate system has a memory, since the state of the climate for one year will have some influence on the state of the climate for the following year; thus it is critical that the autocorrelation structure be maintained. It is necessary to determine the length $(L)$ of the blocks to be shuffled around in the bootstrap method. The block length $(L)$ was determined using the method presented by Wilks (1997), whereby the time series was modeled as a first-order autoregressive process (cf. Moberg and Jones 2005).

Because of the fact that the autocorrelation differs among stations, one may choose to either use an individual block length for each station, or use a universal block length for all the stations. We chose a universal block length that was equal to the average of all the individual block lengths for the stations in order to keep the test consistent among stations; choosing too large an $L$ value means that the test becomes too restrictive; while choosing too small an $L$ value means that the test is too permissive.

For each resampling, the trend is estimated using the OLS method producing 1000 "plausible" trends. The 2.5 and 97.5 percentiles then provide a $95 \%$ confidence interval. A trend is regarded as significant if the confi- dence interval does not contain a zero trend. Nicholls (2001) argues that classical dichotomous significance testing may not be valid in the kind of analyses conducted in climate research. One of the reasons is that a substantial amount of information may be lost if all values that do not reach significance at a certain probability level are rejected. A greater amount of information may be gained if the strength of the linear trend is examined (by defining a 95\% confidence interval) rather than identifying trends that only reach a specified level of significance.

\section{3) Probability distribution functions}

Probability distribution functions (PDFs) were calculated for four temperature and four precipitation extreme indicators for three different time periods. This was done by binning annual values across their range for the 1926-50, 1951-75, and 1976-2000 intervals. The results were normalized to sum 1 to give the probability distribution. To assess whether the probabilities for the different time periods for each indicator were significantly different or not, we employed a two-tailed Kolmogorov-Smirnov test. This test has a null hypothesis that two PDFs for two time periods are identical.

\section{c. Results}

\section{1) TEMPERATURE EXTREMES}

Overall, there are more significant trends indicating warming compared with the number of significant trends indicating cooling for the 1926-2000 interval (Table 2 and Fig. 2). Although the two shorter intervals (i.e., 1926-60 and 1961-2000) reveal a large percentage of significant trends, they display quite different results from one another (Fig. 3).

In the 1926-2000 period, it is evident that there has been an overall decrease in the ETR and an increase in the GSL over the region. TN90 appears to have increased along the coastal regions while decreasing inland (Figs. 2a-c). The decreasing trend in ETR is reasonably strong with some stations having as much as a $0.7^{\circ} \mathrm{C}$ decade $^{-1}$ decrease. Similarly, there is a strong 

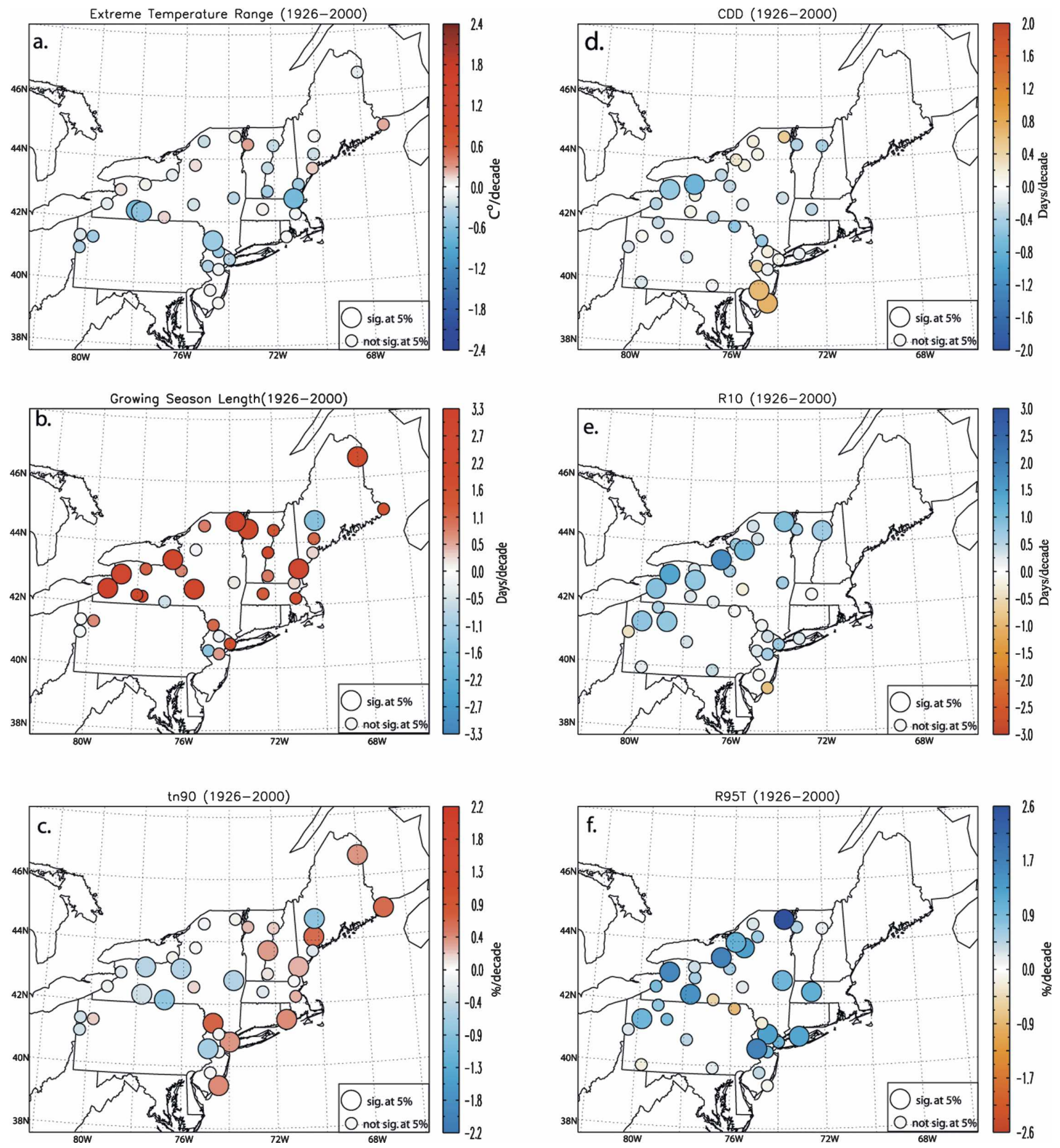

FIG. 2. Trends (a)-(c) for three extreme temperature indices and (d)-(f) three extreme precipitation indices, for the 1926-2000 period. The colors represent the estimated trend. Large circles indicate where significance was reached at the $5 \%$ level.

increasing trend in GSL with some stations having a $\sim 2.2$ days decade ${ }^{-1}$ increase.

In the 1926-60 period, GSL shows a positive trend (Fig. 3b) while ETR and Tn90 (Figs. 3a and 3c) show mixed results. In contrast to the first half of the 19262000 interval, GSL and TN90 show positive trends in the 1961-2000 period while ETR shows negative trends.
When comparing ETR trends between the two periods (Figs. 3a and 3d) there are noticeable differences. In the first period, there was an approximately equal number of stations with increasing and decreasing trends. In contrast, in the second period the majority of stations showed significant decreases in ETR. Differences in FD trends between the two periods show 

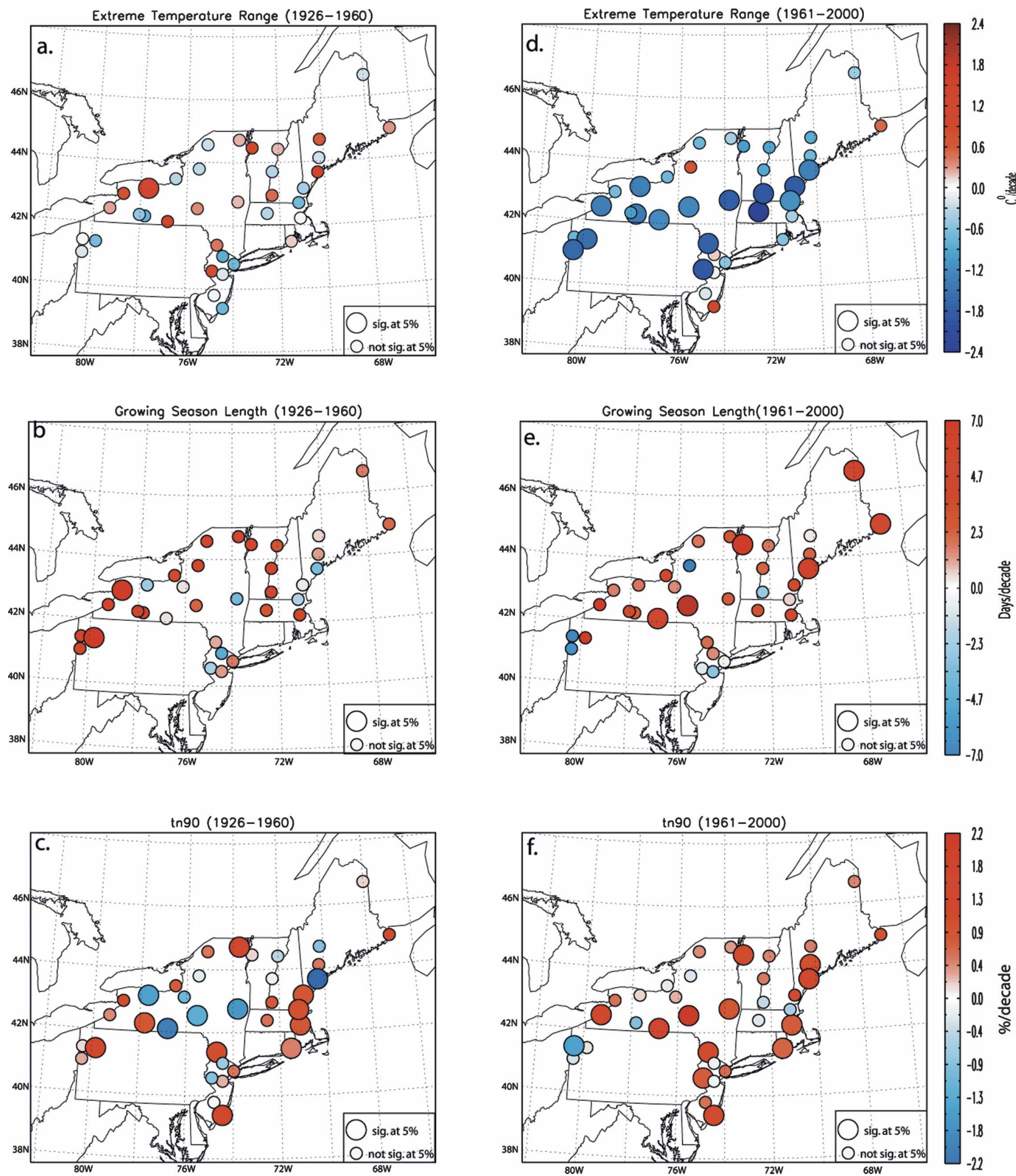

FIG. 3. Trends for three extreme temperature indices for (a)-(c) the 1926-60 period and (d)-(f) the 1961-2000 period. The colors represent the estimated trend. Large circles indicate where significance was reached at the $5 \%$ level.

subtle differences (Table 2). The first period shows that $16 \%$ of the stations had a significant positive trend (cooling) while only $5 \%$ had a significant negative (warming) trend. In contrast, in the latter period this situation was reversed, with only $3 \%$ of the stations having a positive trend while $16 \%$ had a negative trend. GSL shows increasing trends in both periods (Figs. 3b and $3 \mathrm{e})$. The noticeable differences between the two 
periods are that the second period has a greater percentage of significant warming trends. The HWDI shows a dramatic positive trend in the first period with $37 \%$ of the stations having a significant trend (Table 2). In contrast, the second period shows mixed results with $13 \%$ of the stations having significant positive trends and $13 \%$ of the stations having significant negative trends (Table 2). TN90 in the first period showed both positive and negative trends, with $23 \%$ of the stations showing significant positive trends and $13 \%$ showing significant negative trends (Table 2; Fig. 3c). In contrast, in the second period the majority of stations showed a marked increasing trend in warm nights with $31 \%$ of the stations showing significant warming and only $3 \%$ of the stations showing significant cooling (Table 2; Fig. 3f).

\section{2) Precipitation extremes}

Significant positive trends for the four wetness indices are common for the 1926-2000 period (Table 3 and Figs. 2d-f), indicating wetter conditions. Although, there is evidence of significant trends in the two shorter intervals, they display quite different results from one another. Differences between these two intervals are displayed in Fig. 4.

From Fig. $2 d$ it is evident that, with the exception of southern New Jersey, the majority of stations indicate a decrease in CDD over the 1926-2000 period. However, the percentage of stations with significant positive trends equals the percentage of stations with significant negative trends (Table 3). R10 has increased over the longer interval with $26 \%$ of the stations having significant positive trends; most of these stations are located inland (Fig. 2e). The SDII is the indicator with the largest percentage of significant increasing trends, with $41 \%$ having significant positive trends and only $6 \%$ having significant negative trends (Table 3 ). The stations with significant positive trends are generally located at the western boundary of New York State and northern New Jersey (not shown). Similarly, R95T shows a large percentage of stations with significant positive trends (Fig. 2f).

In the 1926-60 period CDD and R10 show regions indicating both positive and negative trends, while R95T shows that the majority of stations have had an increasing trend toward wetter conditions (Figs. 4a-c). In contrast, all the extreme precipitation indices for the 1961-2000 period show the majority of stations having trends toward wetter conditions (Figs. 4d-f).

There is a general drying pattern displayed by CDD for the 1926-60 period (Fig. 4a) with some stations having an increase of 1.6-2.0 days in the maximum number of consecutive dry days per decade. However, only two stations have a significant increase and one had a significant decrease. The later period shows a general reduction in the maximum number of consecutive dry days, with only a few exceptions (Fig. 4d). Although only $12 \%$ of the stations have statistically significant trends, the spatial coverage of decreasing trends for CDD is consistent across most of the region.

There is a mixture of stations showing increasing and decreasing trends for heavy precipitation days (R10) in the earlier period (Fig. 4b) with only one station in western New York having a significant trend, but there is clear evidence for an increase in this indicator throughout the region for the 1961-2000 period (Fig. 4e) with $29 \%$ (Table 3 ) of the stations having significant trends. Some stations experienced a 2.5-3.0 days per decade increase in R10.

$\mathrm{R} 95 \mathrm{~T}$ in the earlier period shows a general pattern toward wetter conditions with some exceptions (Fig. 4c). In contrast to the 1926-60 period, the 1961-2000 period shows a dominance of significant positive trends over western Pennsylvania and New York and also northern Vermont (Fig. 4f). These significant trends occur in $35 \%$ of the stations for the region (Table 3).

\section{3) Probability distribution functions}

Figures 5a-d show the PDFs for four annual precipitation extreme indicators. From these figures it is evident that there has been a marked increase in the three wetness indices and a decrease in the dryness indicator over the period. Figure 5a shows a reduction in the number of CDD, especially over the 1976-2000 period. There has also been a marked increase in the percentage of very wet days (R95T), with again the 1976-2000 period showing the biggest change (Fig. 5c). Figure 5d shows the simple daily intensity index (SDII), which again shows a pronounced increase, particularly over the latter interval.

For all the indices, except heavy precipitation days (R10), the PDF for the most recent time interval (i.e., 1976-2000) is significantly different from the two other intervals. This indicates a shift in the distribution toward wetter conditions over the past three decades.

The PDFs for the temperature indices also reveal patterns of change (Figs. 6a-d). GSL increased markedly over the interval, with the biggest change occurring over the most recent period. Similarly, warm nights (TN90) reveal a marked increase over the interval with the most recent period showing the biggest change (Fig. 6c). The PDFs for FD and ETR (Figs. 6a and 6d, respectively) do not demonstrate as big a change as in GSL and TN90. The PDF for the most recent period for both GSL and TN90 is significantly different from the two earlier periods, which again demonstrates a pro- 

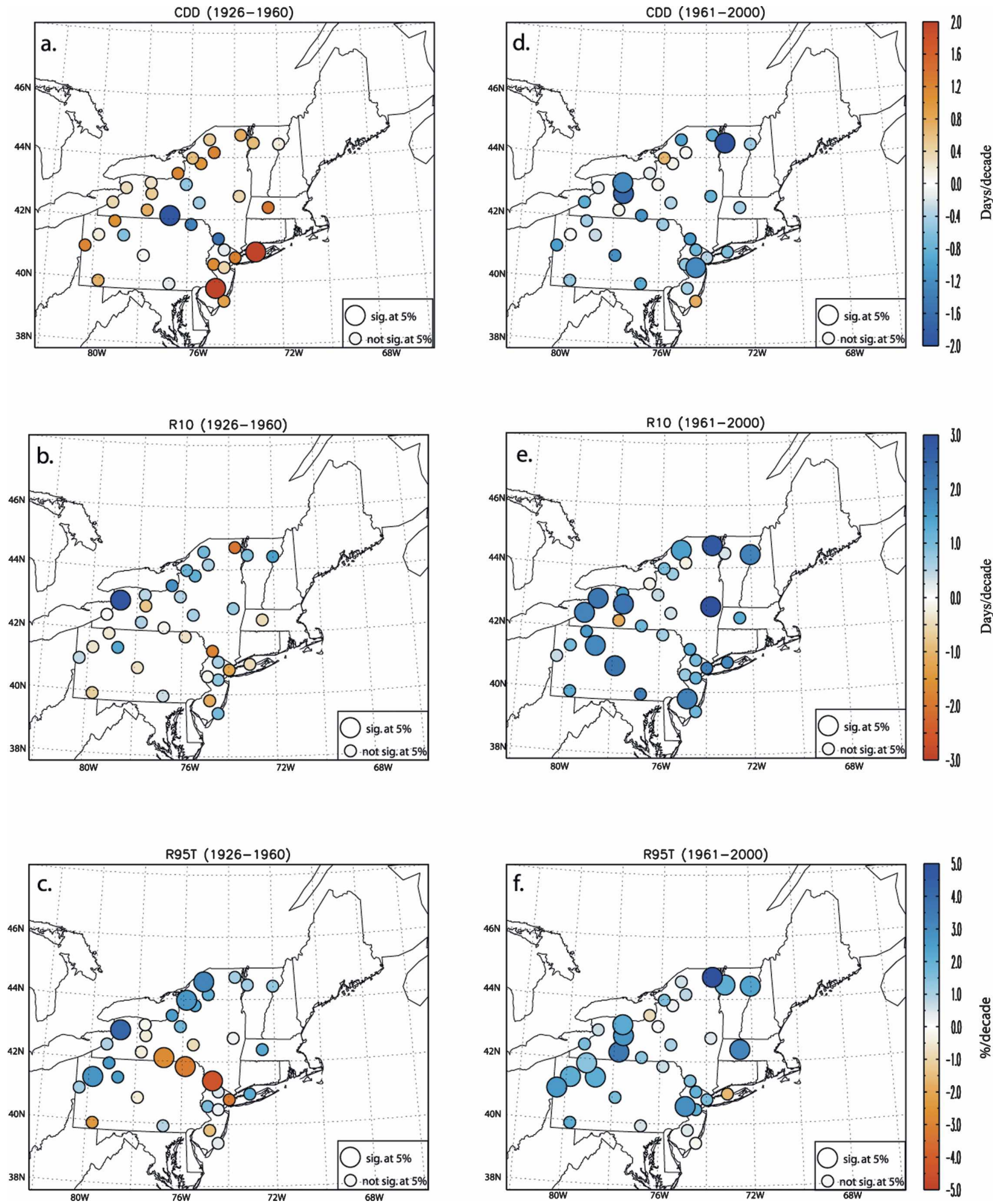

FIG. 4. Same as in Fig. 3, but for precipitation indices. Large circles indicate where 95\% significance was reached. 
TABLE 3. Percentage of stations with trends in precipitation indices that are significant at the $5 \%$ level.

\begin{tabular}{|c|c|c|c|c|c|c|}
\hline \multirow[b]{2}{*}{ Extreme indicator } & \multicolumn{2}{|c|}{ 1926-2000 } & \multicolumn{2}{|c|}{$1926-60$} & \multicolumn{2}{|c|}{ 1961-2000 } \\
\hline & Positive & Negative & Positive & Negative & Positive & Negative \\
\hline R10 & 26 & 0 & 3 & 0 & 29 & 0 \\
\hline $\mathrm{CDD}$ & 6 & 6 & 6 & 3 & 0 & 12 \\
\hline $\mathrm{R} 5 \mathrm{~d}$ & 12 & 3 & 0 & 3 & 21 & 0 \\
\hline SDII & 41 & 6 & 12 & 12 & 24 & 0 \\
\hline R95T & 35 & 0 & 12 & 9 & 35 & 0 \\
\hline
\end{tabular}

nounced shift toward warmer conditions over the past three decades.

\section{Influence of atmospheric circulation modes on winter extremes}

In this section, we examine the interactions between three modes of atmospheric circulation (i.e., AO, PNA,

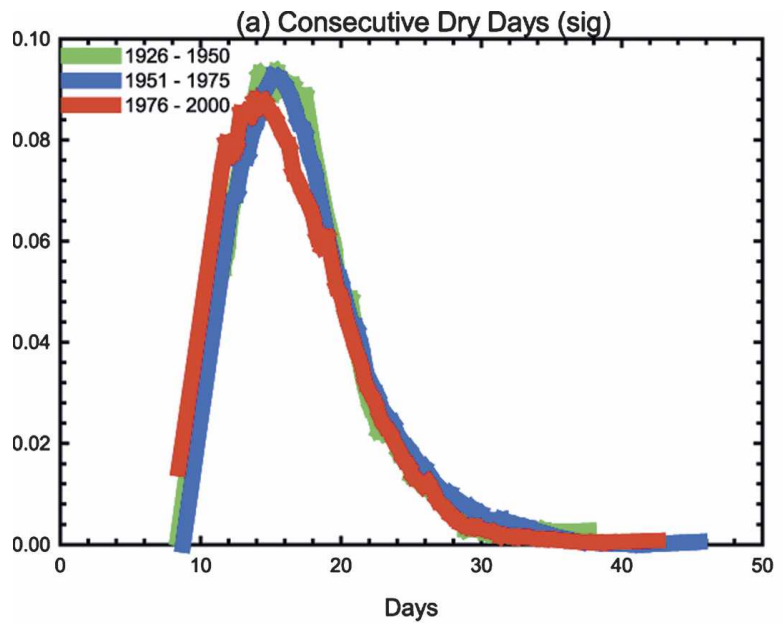

(c) Very Wet Days (sig)

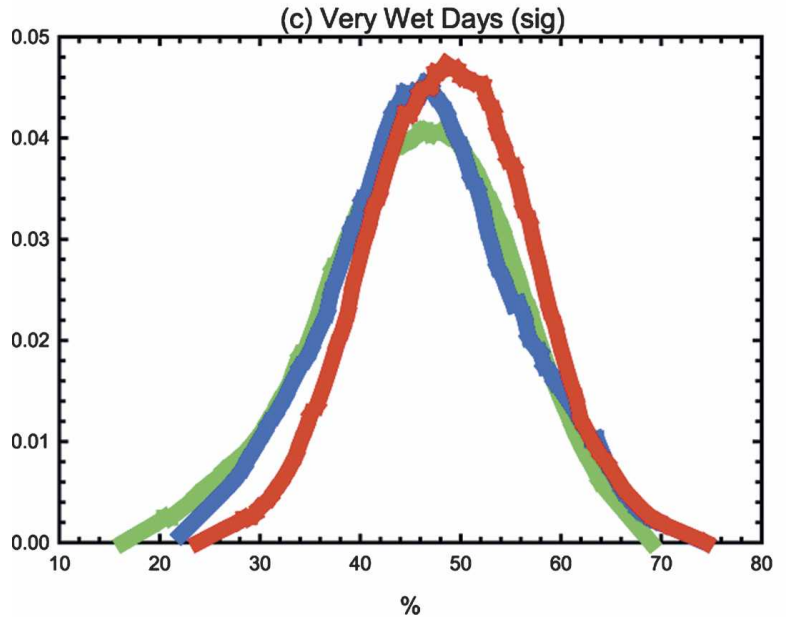

and ENSO) and winter extremes of both temperature and precipitation using various statistical techniques. It should be noted that this kind of analysis may be sensitive to the particular circulation index selected [e.g., the Southern Oscillation index (SOI) versus the Niño3.4 SST index]. This reflects the fact that not all "El Niños," for example, are identical and each one may not have the same teleconnection patterns. The follow-
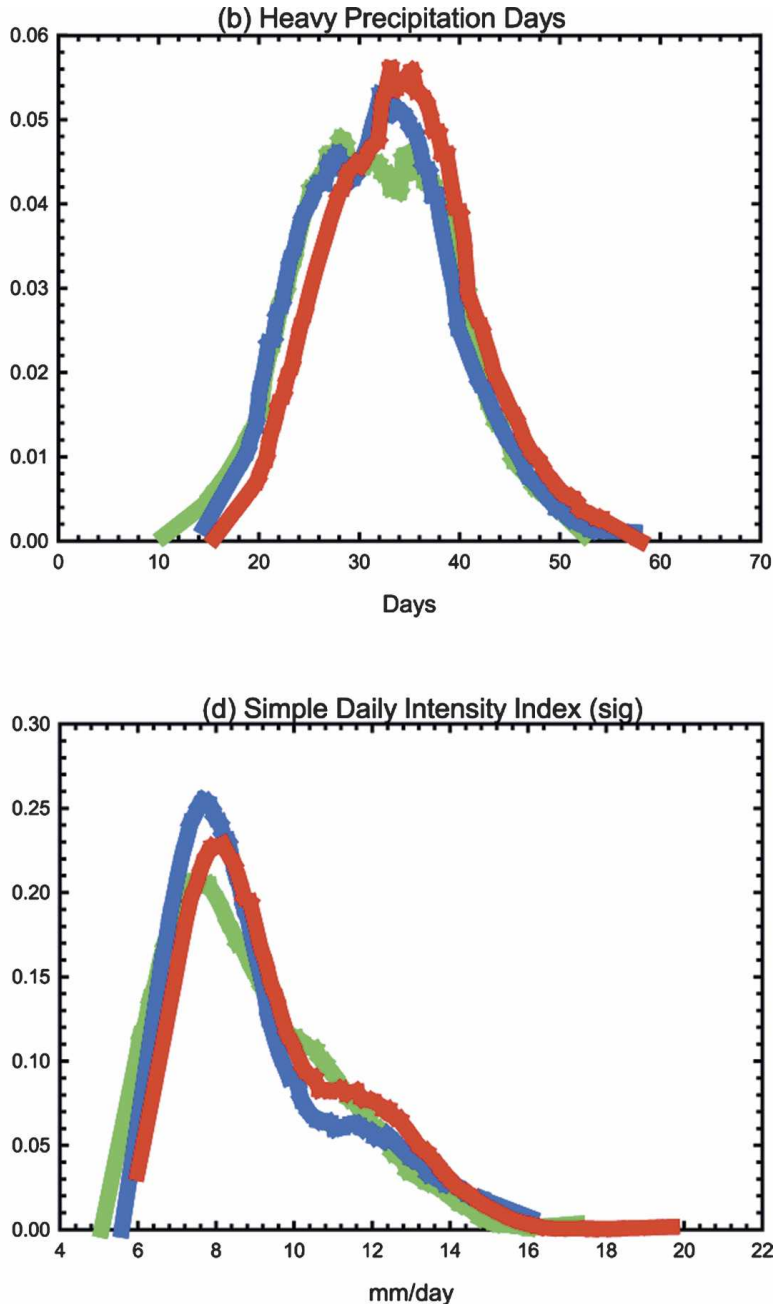

FIG. 5. Annual probability distribution functions for (a) CDD, (b) R10, (c) R95T, and (d) SDII between 1926 and 2000 for the three time periods: 1926-50 (green), 1951-75 (blue), and 1976-2000 (red). 

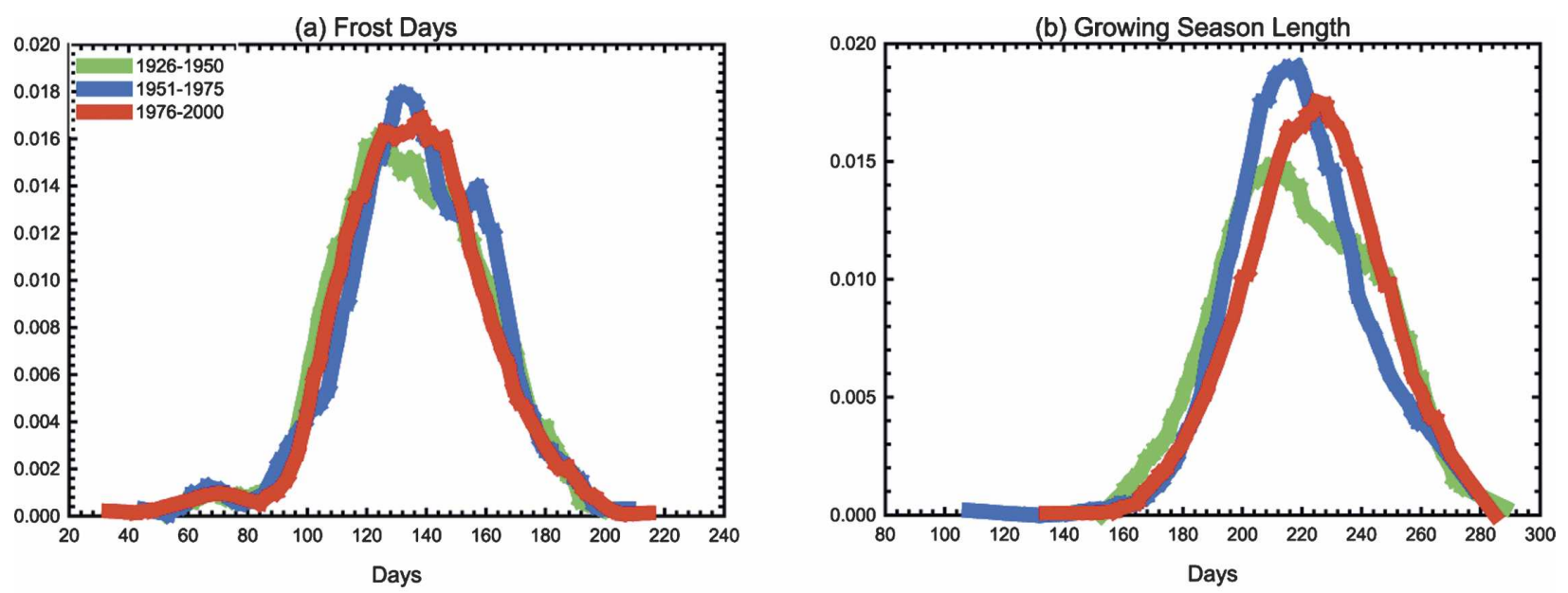

(c) Warm Nights (sig)

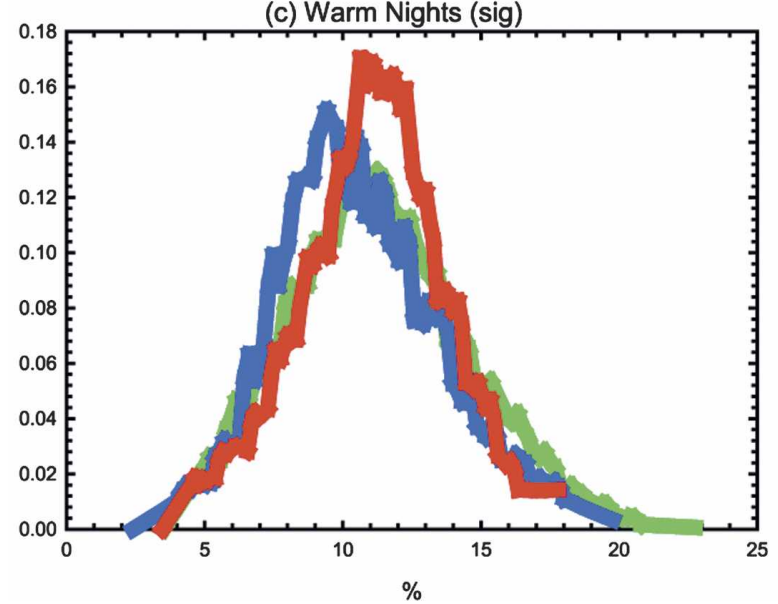

(d) Extreme Temperature Range

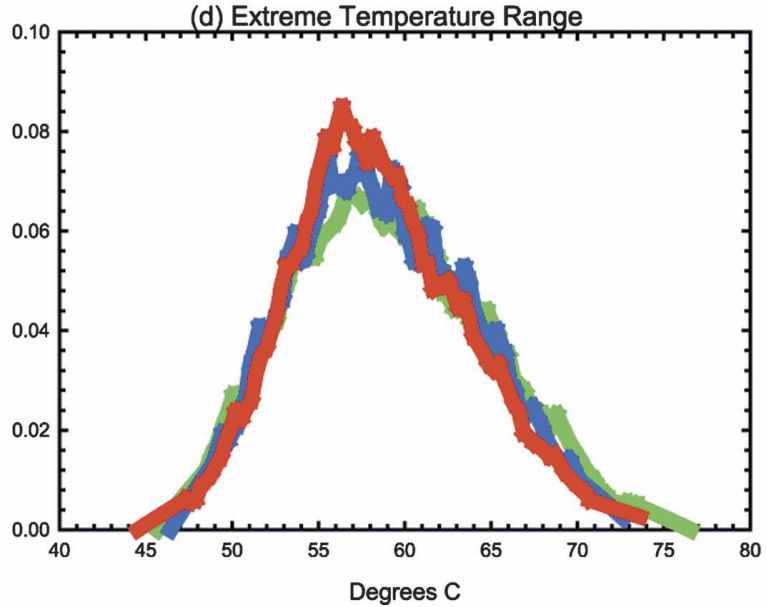

FIG. 6. Annual probability distribution functions for (a) FD, (b) GSL, (c) TN90, and (d) ETR between 1926 and 2000 for the three time periods: 1926-50 (green), 1951-75 (blue), and 1976-2000 (red).

ing results should therefore be interpreted cautiously, particularly when the sample size is small.

\section{a. Data}

The AO is the dominant mode of nonseasonal sea level pressure (SLP) variations north of $20^{\circ} \mathrm{N}$ and is characterized by SLP anomalies of opposite sign in the Arctic and centered about $37^{\circ}-45^{\circ} \mathrm{N}$. The winter AO index (DJFM) can be defined as the leading EOF of the sea level pressure field or of the zonally symmetric geopotential height or zonal wind fields. This index is computed based on the methodology of Thompson and Wallace (2000) and is available online (http://www. atmos.colostate.edu/ao/Data/ao_index.html).

El Niño and La Niña winters were defined based on the Niño-3.4 index. This index is increasingly becoming more popular as an ENSO index due to the fact that
SSTs most involved in ENSO are located in the central Pacific Ocean, and not in the coastal waters off of Peru (Trenberth and Hoar 1996). The Niño-3.4 index is calculated as the average SST for the area $5^{\circ} \mathrm{S}-5^{\circ} \mathrm{N}, 120^{\circ}-$ $170^{\circ} \mathrm{W}$.

The PNA pattern describes the character of midtropospheric airflow across North America (Wallace and Gutzler 1981). This index is derived from a rotated principal component analysis of 700-mb height anomalies for the Northern Hemisphere. This index was averaged for the winter months; it is during these months that this index has the greatest influence on northeast U.S. climate. During a positive (negative) phase of the PNA, the airflow across North America tends to be more meridional (zonal). The PNA index was obtained from the National Centers for Environmental Prediction (NCEP) Climate Prediction Center's (CPC's) Northern Hemisphere teleconnection pattern analysis 
(see http://www.cpc.ncep.noaa.gov/products/precip/ CWlink/pna/pna.shtml).

\section{b. Methods}

\section{1) EMPIRICAL ORTHOGONAL FUNCTION ANALYSIS}

Station data were interpolated using an inverse distance method to produce a gridded dataset with a $0.5^{\circ}$ latitude $\times 0.5^{\circ}$ longitude resolution. This was to avoid problems associated with computing empirical orthogonal functions (EOFs) on irregularly spaced data (Karl et al. 1982) Separate rotated EOF analyses were conducted on the station datasets of four winter extremes: FD, TN90, CDD, and R95T.

The EOF analysis was based on the correlation matrix to empirically resolve the spatial loading patterns and time series (principal component scores) that explain the most variance in northeast temperature and precipitation extremes. The number of EOFs retained was based on determining a break in the scree plot of eigenvalues (Wilks 1995). The higher-order components were removed because they explained little overall variance. The remaining EOFs were then retained and orthogonally rotated according to the varimax criterion. Richman (1986) recommends the use of EOF rotation for cases such as this, in which PC scores are to be used as indices representing physical modes of climate variability.

The temporal and spatial structure of these two temperature extremes (i.e., FD and TN90) and two precipitation (i.e., CDD and R95T) extremes was analyzed over the winter (DJFM) months using this varimax rotated EOF analysis for the 1950 to 2000 period. The month of March was included as the northeast United States typically experiences winter weather (i.e., the polar front is frequently to the south of the region) during March (Ludlam 1976). This analysis was used to determine the dominant modes of variability associated with the seasonal temperature and precipitation extremes in the northeast United States. Although a number of modes were identified in each of the extreme indicators, only the first EOFs for the two temperature extremes will be discussed in the results section.

Once the EOF analysis had been conducted, the principal component scores from each of the four extreme indicators were correlated with the three teleconnection patterns previously addressed. We did not extend our analysis prior to 1950 because the PNA index only extends back to 1950, and we wanted to keep the length of record consistent when calculating correlations between the four extremes and the three teleconnection patterns.

One of the main problems associated with testing multiple hypotheses is that each time a new null hypothesis is tested, the probability of making a type-I error increases geometrically (Brown and Katz 1991). Additional statistical errors arise because climatic data often show temporal autocorrelation. We used Monte Carlo simulations to establish critical $r$ values for the correlation analyses between the teleconnections (independent variables) and the four winter extreme indicators (dependent variables). These simulations were used to set conservative significance levels and thus account for any autocorrelation in each time series. For a detailed description of the methods, refer to Bradbury et al. (2002).

\section{2) Combined AO And ENSO compositing}

An extremely difficult challenge in the study of teleconnection patterns and their association with winter extremes is that ENSO events and AO phases vary in length and magnitude over time. Hence, a lot of variability associated with these extremes may occur during a given phase of either pattern.

To examine the possible interactions that the ENSO and AO collectively have on winter extremes in the northeast United States, winter composites of FD, TN90, CDD, and R95T were calculated during phases of these different teleconnection patterns. This analysis involved calculating the average for the four extremes under nine separate scenarios for both the ENSO and AO conditions. The ENSO and AO events were classified as follows: winters with mean Niño-3.4 SST values greater than (less than) 1 standard deviation were classified as El Niño (La Niña) years while remaining years were classified as ENSO neutral; winters with average $\mathrm{AO}$ values exceeding $0.5(-0.5)$ standard deviations were classified as positive (negative) $\mathrm{AO}$ events while the remaining years were classified as AO neutral. The groups of winter extremes sharing the same characteristics with respect to the ENSO and AO were averaged over the 1926 to 2000 period to determine the extreme anomalies associated with simultaneous AO and ENSO conditions.

After the average values for each station were determined for the different scenarios, they were gridded using an inverse distance method (see EOF methods section). To assess significance of gridpoint values in each composite, we applied a bootstrap method to obtain $95 \%$ confidence levels. We applied our bootstrap method to each grid point separately, choosing with replacement a time series from the original and then calculating averages for $n$ random years. The value $n$ is the number of years used to calculate the averages for the nine composites. We used 2000 iterations to calculate confidence levels. 
TABLE 4. Correlation coefficients $(r)$ between EOF factor scores of two precipitation and two temperature extreme indicators and the three teleconnection indices during winter for the period 1950-2000.

\begin{tabular}{|c|c|c|c|c|c|}
\hline & Teleconnection pattern & EOF1 & EOF2 & EOF3 & EOF4 \\
\hline \multicolumn{6}{|c|}{ Precipitation } \\
\hline \multicolumn{6}{|c|}{ CDD } \\
\hline & $\mathrm{AO}$ & 0.07 & -0.09 & 0.14 & 0.17 \\
\hline & PNA & -0.09 & -0.10 & -0.09 & $-0.39 * *$ \\
\hline & ENSO & 0.02 & -0.24 & 0.00 & $-0.39 * *$ \\
\hline \multicolumn{6}{|l|}{ R95T } \\
\hline & $\mathrm{AO}$ & 0.07 & 0.04 & $0.30 *$ & $0.21 *$ \\
\hline & PNA & 0.24 & -0.23 & $-0.38 * *$ & -0.02 \\
\hline & ENSO & -0.03 & -0.05 & $-0.31 *$ & $-0.34 *$ \\
\hline \multicolumn{6}{|c|}{ Temperature } \\
\hline \multicolumn{6}{|l|}{ FD } \\
\hline & $\mathrm{AO}$ & $-0.33^{*}$ & -0.19 & 0.05 & 0.18 \\
\hline & PNA & $0.25^{*}$ & 0.08 & 0.01 & 0.08 \\
\hline & ENSO & $-0.28 *$ & -0.17 & 0.05 & 0.02 \\
\hline \multicolumn{6}{|l|}{ TN90 } \\
\hline & $\mathrm{AO}$ & $0.48^{* *}$ & 0.00 & 0.04 & 0.09 \\
\hline & PNA & -0.11 & -0.05 & -0.19 & 0.08 \\
\hline & ENSO & -0.08 & 0.05 & $-0.34 *$ & 0.11 \\
\hline
\end{tabular}

* Significant at the 0.05 level.

** Significant at the 0.01 level.

\section{c. Results}

\section{1) EOF ANALYSIS}

This EOF analysis aims to delineate modes of regional significance. The correlation statistics between the four EOF factor scores of the winter extremes and the teleconnection patterns are given in Table 4. These correlation statistics vary widely, with EOF1 generally displaying the highest values for the temperature indices and EOF3 and EOF4 the highest for the precipitation indices.

For CDD EOF4 shows a significant correlation with the PNA and the ENSO indices, while EOF3 for R95T shows a significant correlation with all three teleconnections (Table 4). The leading EOF for both FD and TN90 reveals a significant correlation with the AO. Figure 7 shows the EOF factor scores of the two leading EOFs of DJFM TN90 and FD along with the AO over the northeast U.S. region.

The leading EOF for TN90, which explains $29 \%$ of the variance, shows a strong correlation with the AO (Table 4; Fig. 7a; i.e., during a positive phase of the AO, there is a higher chance of there being more warmer nights for a given winter). From 1950 to $\sim 1968$ there was a decreasing trend for the AO index and a corresponding decreasing trend for Tn90; from $\sim 1969$ to 2000 there was an increasing trend for the AO index with a corresponding increasing trend for TN90. As with TN90-EOF1, the AO- and FD-EOF1 show similar trends, with a decreasing (increasing) AO trend cor- responding with an increasing (decreasing) FD trend (Fig. 7b). Thus, over the 1950 to 2000 period, some of the variability associated with the changes in TN90 and FD may be attributed to changes in the phase of the AO.

\section{2) Combined AO And ENSO composites}

During a negative phase of the $\mathrm{AO}$, there were fewer TN90s with an El Niño event over the region, with the exception of Maine (Fig. 8). The same holds true for a neutral ENSO while during a La Niña, the general pattern is similar with the exception of Maine, which now has fewer warm nights. The notable feature associated with the negative AO phase is the observed belowaverage warm nights during all phases of the ENSO. Another interesting feature, associated with negative AO conditions, is the above-average warm nights in Maine during an El Niño and neutral ENSO; Wettstein and Mearns (2002) noted similar patterns.

When the AO is in its positive phase, the region tends to have above-average warm nights in all phases of the ENSO. The region experiences the most warm nights during the El Niño phase, as compared with the other two ENSO phases. During the neutral phase of the $\mathrm{AO}$, there are generally fewer warm nights during a neutral ENSO and La Niña; while during an El Niño, there are above-average warm nights. From Fig. 8 it is evident that the phase of the AO has a greater influence on the percentage of winter warm nights than the ENSO phase, indicating that the AO is the dominant 

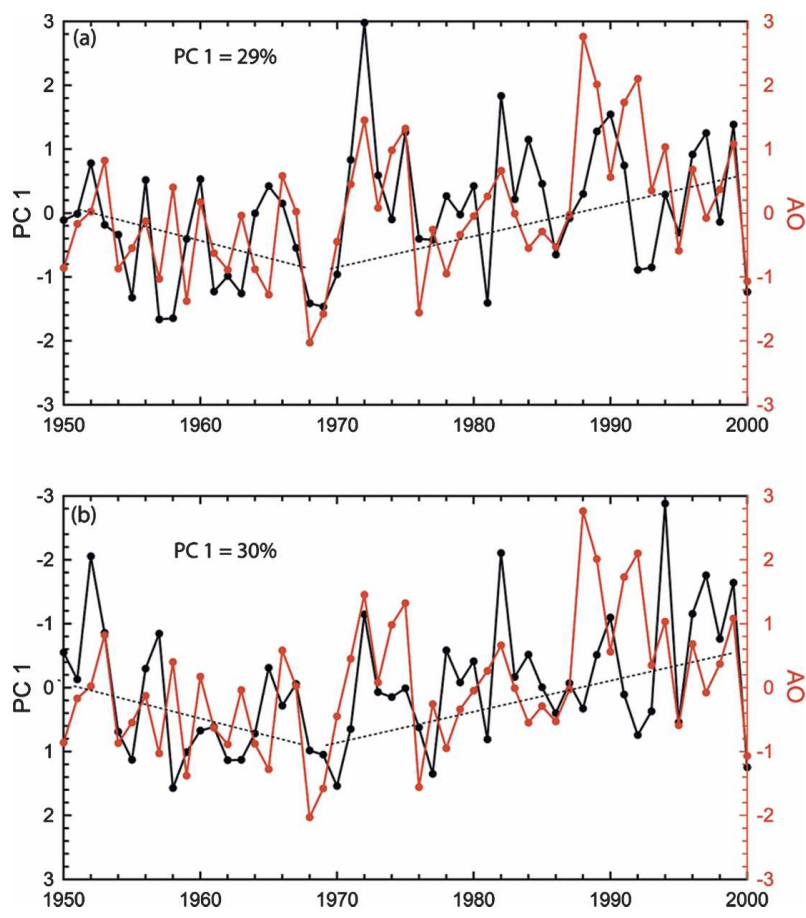

FIG. 7. Leading EOF factor scores (black) and AO (red) of DJFM for (a) warm nights (TN90) and (b) frost days in the northeast United States. Principle component 1 (PC1) for warm nights explains $29 \%$ of the variance while PC1 for frost days explains $30 \%$ of the variance.

mode of atmospheric circulation affecting this parameter.

The fewest consecutive dry days occur during a La Niña combined with a positive and neutral AO (Fig. 9). In comparison, the most above-average consecutive dry days occur during an El Niño combined with a negative AO. During a neutral ENSO, there are typically fewer consecutive dry days regardless of the $\mathrm{AO}$ phase across the region. A high level of confidence may be placed on this result as $n$ values are quite large. On a broader scale it is evident that the number of winter consecutive dry days appears to be more dependent on the ENSO phase than on the AO phase. However, in their study of the combined impacts of ENSO and AO, Zhou and Higgins (2001) noted that the AO has a larger impact on precipitation extremes across the United States when the combined effect of the ENSO and AO are considered.

\section{Discussion and conclusions}

Throughout the 1926-2000 interval, the most prominent feature of the temperature extremes is that GSL has increased significantly at several stations. GSL demonstrates an increasing trend in both of the shorter intervals. A greater percentage of the stations in the latter interval, however, contain statistically significant trends. Comparing the two intervals, where the first demonstrates a 0.4 day decade ${ }^{-1}$ regional trend and the second demonstrates a 3.8 day decade ${ }^{-1}$ regional trend, reveals the substantial increase in the GSL over the past four decades.

Another noteworthy feature is the significant decrease in the ETR over the 1926-2000 interval. Much of this decreasing trend, however, is attributed to the sharp decline from 1961 to 2000 . Alexander et al. (2006) showed that over the majority of global land areas, including the northeast United States, ETR has shown a systematic and statistically significant decline over the past five decades. Reductions during the second half of the twentieth century are often as large as several degrees and are mainly associated with increasing nighttime temperatures (Tuomenvirta et al. 2000).

There has been an overall decrease in the number of FD during the 1961-2000 interval. This regional trend is consistent with the pattern of mean annual temperature change shown in Karl et al. (1996). Their analysis showed substantial warming for most of the United States, and in particular the northeast United States. The decrease in FD is highlighted by the results obtained by Easterling (2002). In his analysis, he concluded that there has been an overall decrease in FD for the 1948-99 period for the northeast U.S. region. Additionally, Alexander et al. (2006) documented that $40.6 \%$ of global land areas have had a decrease in FD. Studies of FD in other Northern Hemisphere regions have found similar results to those in this study. For example, Bonsal et al. (2001) found decreasing FD in Canada during the twentieth century, and similarly, Heino et al. (1999) and Klein Tank and Können (2003) found decreasing FD in Europe.

During the 1926-60 period, the majority of stations had a significant increase in HWDI, with the region overall having a 0.6 day per decade increase (figure not shown). There is much regional variation in the trends associated with the number of days exceeding some threshold (e.g., HWDI). Over the United States as a whole, days exceeding a certain threshold are dominated by past large anomalies, which is partially the result of dry land surface conditions during the droughts of the 1930s and 1950s. There has thus been an overall slight downward trend in the number of these extremes over the United States, despite an overall increase in mean temperature (Easterling et al. 2000b). In an analysis of maximum and minimum temperature threshold exceedances in the northeast United States, DeGaetano (1996) found an increase in the occurrence 
El Niño
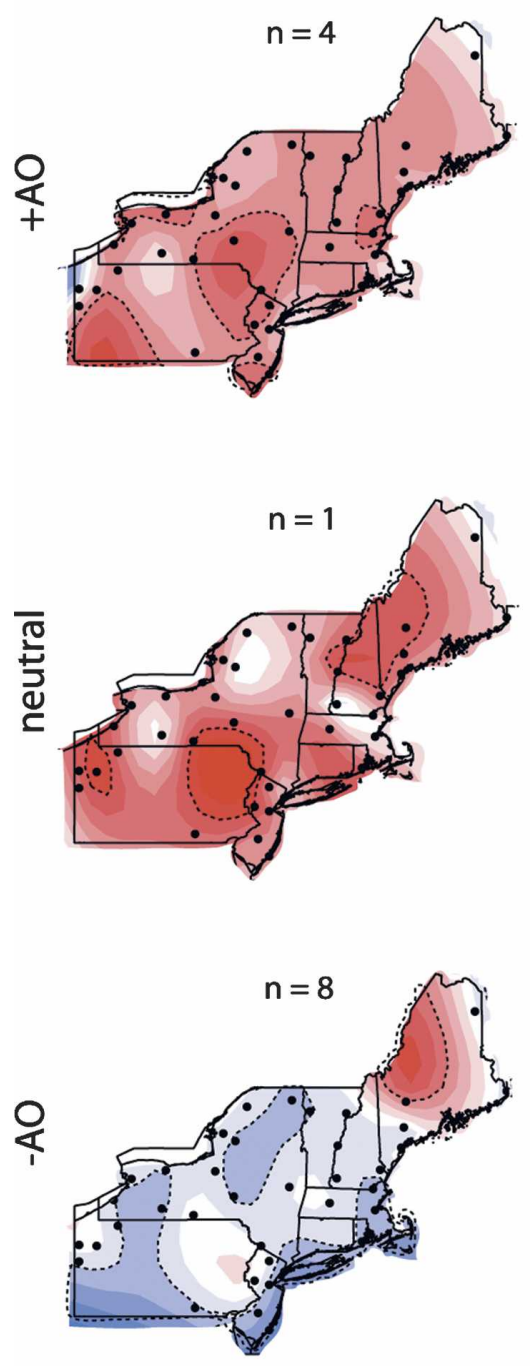

neutral
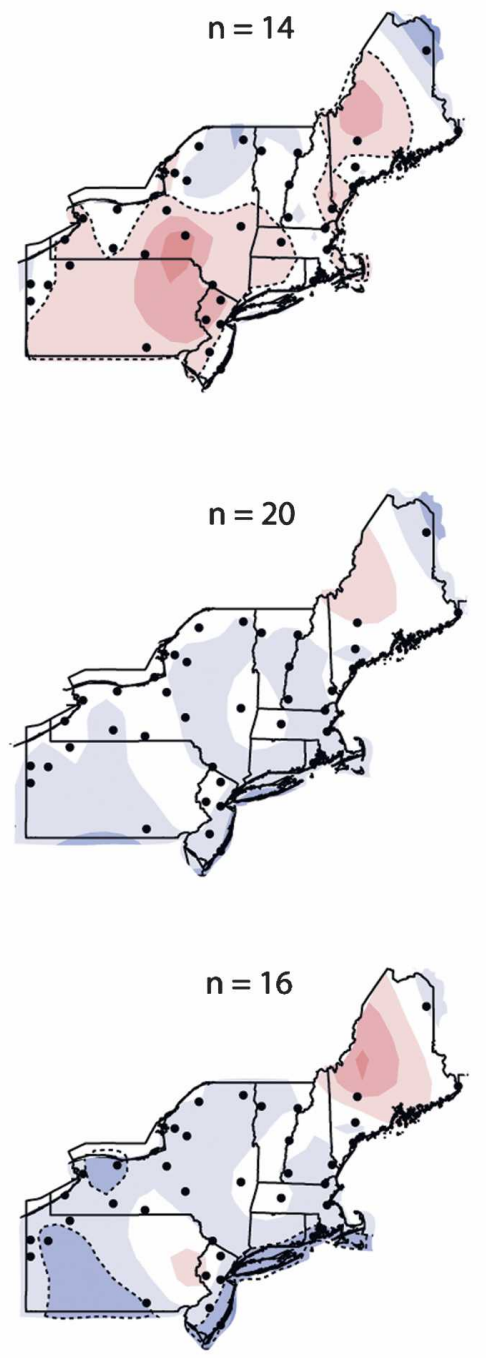

La Niña
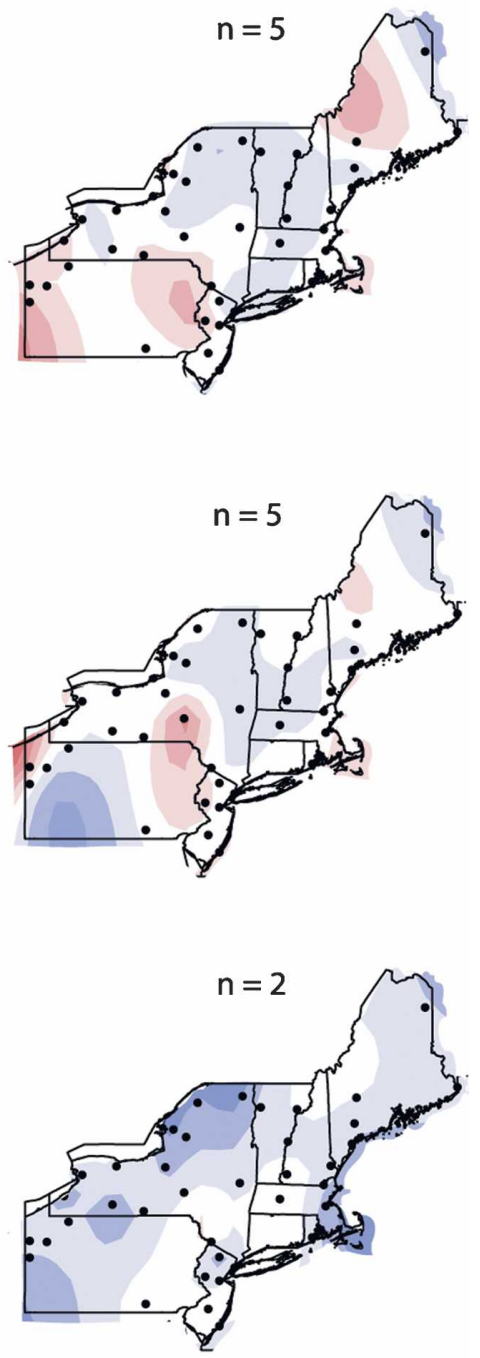

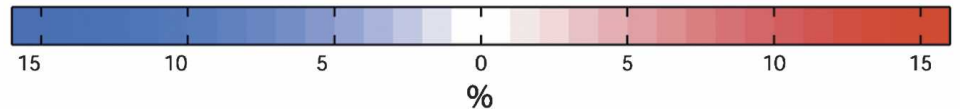

FIG. 8. Composites of winter (DJFM) TN90 anomalies during the different phases of the ENSO and AO. Areas located within the dashed lines are significant at the 5\% level. The number of years $(n)$ used in each composite is shown above each plot. Black dots represent each station used.

of minimum temperatures $\geq 21.1^{\circ} \mathrm{C}$ at all but 2 of the 13 stations for the 1951 to 1993 period. Similarly, he found an increase in the number of days with a minimum temperature $\geq 18.3^{\circ} \mathrm{C}$ at $76 \%$ of the stations for the period. Alexander et al. (2006) showed a global increase in warm nights, and, in particular, an increase in the northeastern United States.

The positive trends in the northeastern U.S. precipitation extreme indices support the statement by Houghton et al. (2001) that "it is likely that there has been a statistically significant increase in the amount of heavy and extreme precipitation events when averaged across the mid and high latitudes." During the 1926 to 2000 interval, all of the regional extreme precipitation indices show trends toward wetter conditions. Of the five indices, R10 and R95T demonstrate the most convincing patterns, with the majority of stations showing significant trends in both of these indices. It is interesting to note that the stations located in the western part of the region show significant trends for R10 and R95T, relative to those located in the central region (cf. Figs. $2 \mathrm{e}, \mathrm{f})$. This pattern may demonstrate the large influence 

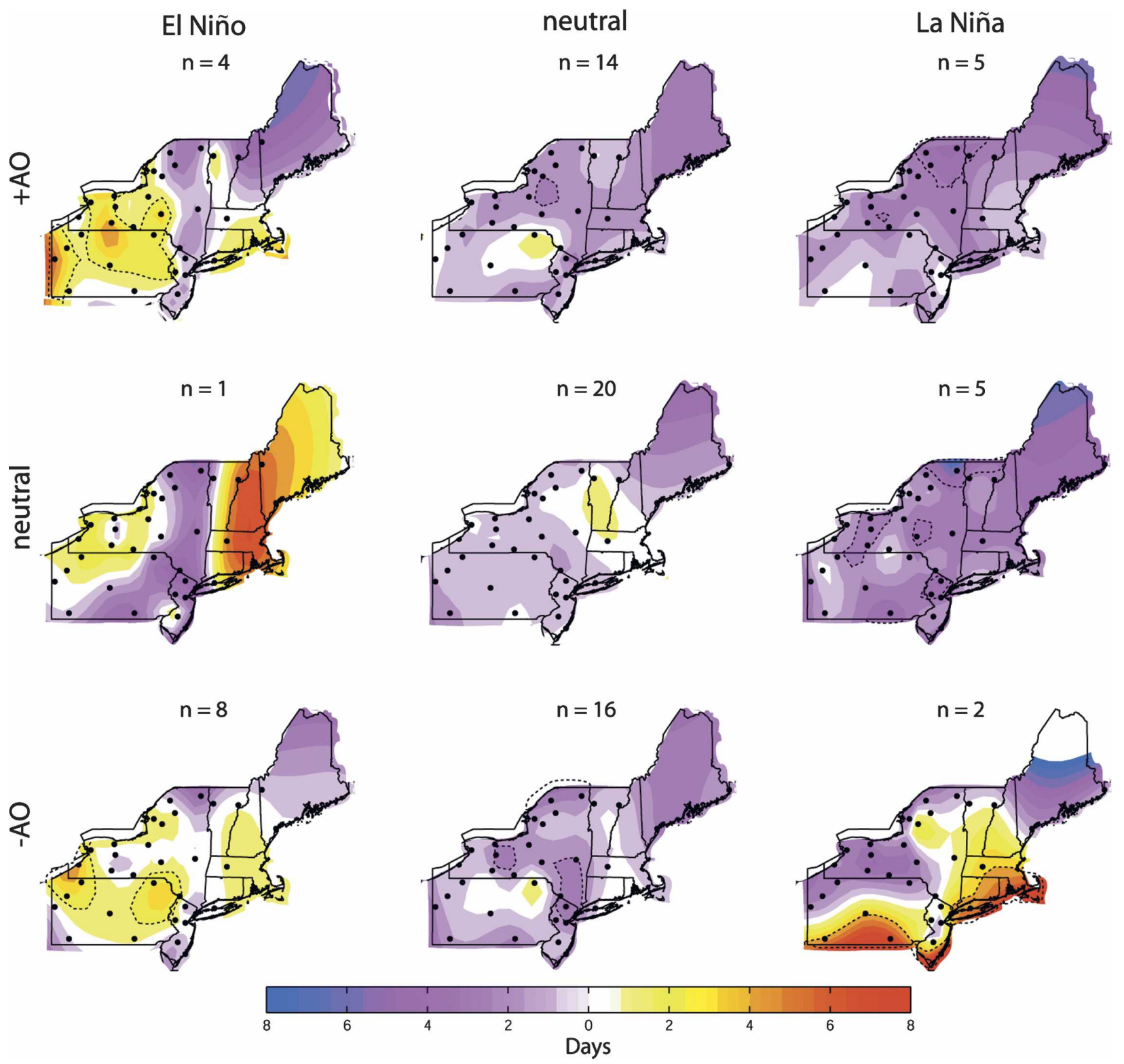

FIG. 9. Same as in Fig. 8, but for CDD anomalies during the different phases of the ENSO and AO for the 1926 to 2000 period.

of Lake Erie and Lake Ontario on precipitation extremes for stations adjacent to the lakes.

Results for the earlier period demonstrate mixed results for the five indices in that some stations experienced positive trends and others experienced negative trends. In comparison, the latter period shows an overwhelming pattern toward wetter conditions for the majority of stations in the region.

For CDD, the earlier period shows a general positive trend toward drier conditions, with the exception of some stations located in the central region. In contrast, the latter period is dominated by stations showing trends toward fewer CDDs, with the region having a
0.5 day per decade decrease. There is considerable variability in dry periods over the twentieth century in the United States, with the droughts of the 1930s and 1950s dominating any of the long-term trends (Karl et al.1996; Kunkel et al. 1996).

Karl et al. (1996) indicate that since about 1970, more of the country has tended to remain excessively wet, with over $30 \%$ of the country experiencing a severe moisture surplus for at least one year in each of the past three decades. Additionally, the proportion of the country with a much greater than normal number of wet days has increased much more than would be expected in a stationary climate. This is especially appar- 
ent between 1910 and 1940 and after 1970. Clean AirCool Planet and Wake (2005) demonstrate that over the past century, precipitation in the northeast United States has increased by $8 \%$. Additionally, R5d increased during the 1980s and 1990s, as compared with the early 1900s. On a global scale, several studies have also shown an increase in precipitation extremes. For example, Alexander et al. (2006) showed that there has been a dramatic increase in global precipitation extremes between the years 1951 and 2003.

The three teleconnection patterns examined play an integral role in determining the temporal nature of temperature and precipitation extremes in the northeast United States. Correlation statistics between the leading EOFs of two temperature (FD and warm nights) and two precipitation (CDD and R95T) extremes during the winter months (DJFM) reveal that some of the variability associated with these four extremes may be explained by the AO, ENSO, and PNA. For the two precipitation extremes, CDD-EOF4 had a significant correlation with the PNA and the ENSO, while R95TEOF3 had a significant correlation with the PNA (Table 4). For the temperature extremes, the leading EOF for both FD and warm nights had a significant correlation with the AO over the past four decades (Fig. 7). This indicates that the dominant mode of variability associated with both winter FD and warm nights may be explained by the $\mathrm{AO}$, and the recent trend in the AO toward the high index phase (e.g., Thompson and Wallace 2000) is consistent with the increase in temperature extremes in recent decades.

The combined effect of the ENSO and AO phenomena has a marked influence on winter warm nights and consecutive dry days. The combined influence may be summarized as follows: positive $\mathrm{AO}$ winters generally produce warmer conditions (i.e., increased TN90) during all phases of the ENSO, while negative $\mathrm{AO}$ winters produce colder conditions. Higgins et al. (2002) found that winters with a low-index phase of the AO are associated with a decrease (an increase) in the number of warm (cold) days at most locations in the United States, while the opposite is true during a high-index phase of the AO. El Niño years generally result in an increase in consecutive dry days for most of the region during a negative $\mathrm{AO}$, while during a neutral and positive AO, approximately half of the region has above (below) average CDDs. There are fewer consecutive dry days during a neutral ENSO regardless of the AO phase. Finally, during La Niña years there are typically fewer consecutive dry days when the $\mathrm{AO}$ is in its positive and neutral phase, while during its negative phase the coastal regions tend to be drier while inland areas wetter.
When the $\mathrm{AO}$ is in its negative phase, there tends to be the lowest number of warm nights when a La Niña prevails, and the most consecutive dry days when an El Niño prevails. When the AO is in its positive phase, there is generally the greatest number of warm nights when combined with an El Niño and the fewest consecutive dry days during a La Niña.

Acknowledgments. We wish to thank James Bradbury for his help using IDL and his insight into New England climate. Ambarish Karmalkar is acknowledged for his statistical help using EOF analysis and his MATLAB programming expertise. We also thank Frank Keimig for his assistance during the analysis and his comments on the manuscript. This study was funded by the NOAA Grant NA030AR4310128.

\section{REFERENCES}

Alexander, L.V., and Coauthors, 2006: Global observed changes in daily climate extremes of temperature and precipitation. $J$. Geophys. Res., 111, D05109, doi:10.1029/2005JD006290.

Bonsal, B. R., X. Zhang, L. A. Vincent, and W. D. Hogg, 2001: Characteristics of daily and extreme temperatures over Canada. J. Climate, 14, 1959-1976.

Bradbury, J. A., S. L. Dingman, and B. D. Keim, 2002: Relation of New England hydroclimate to large-scale atmospheric circulation patterns. J. Amer. Water Resour. Assoc., 38, 1287-1299.

Brown, B. G., and R. W. Katz, 1991: Use of statistical methods in the search for teleconnections: Past, present, and future. Teleconnections Linking Worldwide Climate Anomalies: Scientific Basis and Societal Impact, M. H. Glantz, R. W. Katz, and N. Nichols, Eds., Cambridge University Press, 371-400.

Chelliah, M., 1990: The global climate for June-August 1989: A season of near-normal conditions in the tropical Pacific. $J$. Climate, 3, 138-160.

Clean Air-Cool Planet, C.P. Wake, cited 2005: Indicators of climate change in the Northeast 2005. The Climate Change Research Center, University of New Hampshire. [Available online at http://www.cleanair-coolplanet.org/information/pdf/ indicators.pdf.]

Cooter, E. J., and S. K. Leduc, 1995: Recent frost date trends in the north-eastern USA. Int. J. Climatol., 15, 65-75.

DeGaetano, A. T., 1996: Recent trends in maximum and minimum temperature threshold exceedences in the northeastern United States. J. Climate, 9, 1646-1657.

_ , and R. B. Allen, 2002: Trends in twentieth-century temperature extremes across the United States. J. Climate, 15, 3188 3205.

Easterling, D. R., 2002: Recent changes in frost days and the frostfree season in the United States. Bull. Amer. Meteor. Soc., 83, 1327-1332.

— , T.R. Karl, J.H. Lawrimore, and S.A. Del Greco, 1999: United States Historical Climatology Network daily temperature, precipitation, and snow data for 1871-1997. ORNL/ CDIAC-118, NDP-070. Carbon Dioxide Information Analysis Center, Oak Ridge National Laboratory, Oak Ridge, TN, $84 \mathrm{pp}$.

— J. L. Evans, P. Y. Groisam, T. R. Karl, K. E. Kunkel, and P. Ambenje, 2000a: Observed variability and trends in extreme 
climate events: A brief review. Bull. Amer. Meteor. Soc., 81, 417-425.

—, G. A. Meehl, C. Parmesan, S. A. Changon, T. R. Karl, and L. O. Mearns, 2000b: Climate extremes: Observations, modeling, and impacts. Science, 289, 2068-2074.

Frich, P., L. V. Alexander, P. Della-Marta, B. Gleason, M. Haylock, A. M. G. Klein, and T. Peterson, 2002: Observed coherent changes in climatic extremes during the second half of the twentieth century. Climate Res., 19, 193-212.

Heino, R., and Coauthors, 1999: Progress in the study of climate extremes in northern and central Europe. Climatic Change, 42, 151-181.

Higgins, R. W., A. Leetmaa, and V. E. Kousky, 2002: Relationships between climate variability and winter temperature extremes in the United States. J. Climate, 15, 1555-1572.

Houghton, J. T., Y. Ding, D. J. Griggs, M. Noguer, P. J. van der Linden, X. Dai, K. Maskell, and C. A. Johnson, Eds., 2001: Climate Change 2001: The Scientific Basis. Cambridge University Press, $881 \mathrm{pp}$.

Karl, T. R., A. J. Koscielny, and H. F. Diaz, 1982: Potential errors in the application of principal component (eigenvector) analysis to geophysical data. J. Appl. Meteor., 21, 1183-1186.

— , R. W. Knight, D. R. Easterling, and R. G. Quayle, 1996: Indices of climate change for the United States. Bull. Amer. Meteor. Soc., 77, 279-292.

Kiktev, D., D. Sexton, L. Alexander, and C. Folland, 2003: Comparison of modeled and observed trends in indices of daily climate extremes. J. Climate, 16, 3560-3571.

Klein Tank, A. M. G., and G. P. Können, 2003: Trends in indices of daily temperature and precipitation extremes in Europe, 1946-99. J. Climate, 16, 3665-3680.

Kunkel, K. E., S. A. Changnon, B. C. Reinke, and R. W. Arritt, 1996: The 1995 heat wave in the Midwest: A climatic perspective and critical weather factors. Bull. Amer. Meteor. Soc., 77, 1507-1518.

_, K. Andsager, and D. R. Easterling, 1999: Long-term trends in extreme precipitation events over the conterminous United States and Canada. J. Climate, 12, 2515-2527.

Ludlam, D., 1976: The Country Journal: New England Weather Book. Houghton Mifflin, $147 \mathrm{pp}$.

Moberg, A., and P. D. Jones, 2005: Trends in indices for extremes in daily temperature and precipitation in central and western Europe, 1901-99. Int. J. Climatol., 25, 1149-1171.

Nicholls, N., 2001: The insignificance of significance testing. Bull. Amer. Meteor. Soc., 81, 981-986.

Peterson, T. C., C. Folland, G. Gruza, W. Hogg, A. Mokssit, and N. Plummer, 2001: Report on the activities of the Working Group on Climate Change Detection and related rapporteurs 1998-2001. World Meteorological Organisation Rep. WCDMP-47, WMO-TD 1071, Geneva, Switzerland, 143 pp.

Plummer, N., and Coauthors, 1999: Changes in climate extremes over the Australian region and New Zealand during the twentieth century. Climatic Change, 42, 183-202.

Richman, M. B., 1986: Rotation of principal components. J. Climatol., 6, 293-335.

Thompson, D. W. J., and J. M. Wallace, 2000: Annular modes in the extratropical circulation. Part I: Month-to-month variability. J. Climate, 13, 1000-1015.

Trenberth, K. E., and T. J. Hoar, 1996: The 1990-1995 El NiñoSouthern Oscillation event: Longest on record. Geophys. Res. Lett., 23, 57-60.

Tuomenvirta, H., H. Alexandersson, A. Drebs, P. Frich, and P. O. Nordli, 2000: Trends in Nordic and Arctic temperature extremes and ranges. J. Climate, 13, 977-990.

Wallace, J. M., and D.S. Gutzler, 1981: Teleconnections in the geopotential height field during the Northern Hemisphere winter. Mon. Wea. Rev., 109, 784-812.

Wilks, D. S., 1995: Statistical Methods in the Atmospheric Sciences. Academic Press, 467 pp.

_ 1997: Resampling hypothesis tests for autocorrelated fields. J. Climate, 10, 65-82.

Williams, C. N., Jr., R.S. Vose, D. R. Easterling, and M. J. Menne, 2004: United States Historical Climatology Network daily temperature, precipitation, and snow data. ORNL/CDIAC118, NDP-070.

Zhou, Y., and R. W. Higgins, 2001: Relationships between climate variability and the statistics of winter precipitation extremes in the United States. Proc. 26th Annual Climate Diagnostic and Prediction Workshop, La Jolla, CA, NCEP/Climate Prediction Center and Scripps Institution of Oceanograph, 16.7. [Available online at http://www.cpc.ncep.noaa.gov/products/ outreach/proceedings/cdw26_proceedings/.] 